\title{
Lymphocytes, neuropeptides, and genes involved in alopecia areata
}

\author{
Amos Gilhar, ${ }^{1}$ Ralf Paus, ${ }^{2}$ and Richard S. Kalish ${ }^{3}$
}

${ }^{1}$ Skin Research Laboratory, The Ruth and Bruce Rappaport Faculty of Medicine, Technion — Israel Institute of Technology and Flieman Medical Center, Haifa, Israel. 'University Hospital Schleswig-Holstein, University of Lübeck, Lübeck, Germany. ${ }^{3}$ Department of Dermatology, School of Medicine, Stony Brook University, Stony Brook, New York, USA.

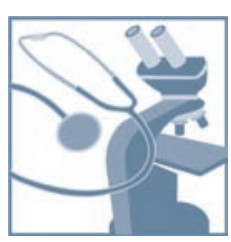

Many lessons in autoimmunity - particularly relating to the role of immune privilege and the interplay between genetics and neuroimmunology - can be learned from the study of alopecia areata, the most common cause of inflammation-induced hair loss. Alopecia areata is now understood to represent an organ-restricted, $T$ cell-mediated autoimmune disease of hair follicles. Disease induction is associated with collapse of hair follicle immune privilege in both humans and in animal models. Here, the role of HLA associations, other immunogenetic factors, and neuroendocrine parameters in alopecia areata pathogenesis are reviewed. This instructive and clinically significant model disease deserves more widespread interest in the immunology community.

Even though alopecia areata $(\mathrm{AA})$ is one of the most frequently occurring organ-restricted autoimmune diseases in humans (1), mainstream clinical immunology and autoimmunity research have tended to ignore this intriguing $\mathrm{T}$ cell-mediated disease of the hair follicle. This is regrettable, because AA provides an excellent opportunity to study the roles of immunogenetics, immune privilege collapse, and neuroimmune-endocrine factors in a highly instructive and exquisitely accessible human model system of organ-specific autoimmunity $(2,3)$. The existence of excellent related animal models of this condition (4-6) and human hair follicle organ culture systems (7), which can instructively complement in vivo research in the human system, make AA very attractive as a model system for the study of autoimmunity.

AA often results in very significant psychological distress, as the condition often afflicts children and teenagers and can cause sudden and widespread scalp hair loss (AA totalis), or complete body hair loss (AA universalis) (8), with resulting negative effects on the quality of life, psychosocial parameters, and psychoemotional symptoms. Response of severe cases to treatment is problematic, and the condition is deserving of study for both the general lessons it provides and for significantly improving AA management.

\section{Clinical features}

The most common presentation of AA is isolated, round areas of complete hair loss without clinical signs of skin inflammation (Figure 1). Characteristic short hairs tapered toward their base (exclamation point hairs) as well as regrowing white hairs may be present, allowing for rapid clinical diagnosis. The nail matrix may also be affected, resulting in pits in the nail plate or even more severe nail dystrophy (e.g., trachyonychia). While the scalp is the

Nonstandard abbreviations used: AA, alopecia areata; AIRE, autoimmune regulator; APECED, autoimmune polyendocrinopathy-candidiasis-ectodermal dystrophy; IP-10, IFN- $\gamma$-inducible protein 10; MIC, MHC class I chain-related; MIF, macrophage migration inhibitory factor; $\alpha$-MSH, $\alpha$-melanocyte-stimulating hormone; NALP1, NACHT leucine-rich-repeat protein 1 ; NGF, nerve growth factor.

Conflict of interest: A. Gilhar receives research funding from Teva Pharmaceuticals, Perigo Co., and Johnson \& Johnson. R. Paus receives research funding and/or consultancy fees from Henkel Co. (Dusseldorf), Wolff Co. (Bielefeld), and Bielefeld Co. (Hamburg). R.S. Kalish receives research funding from Paradigm Biomedical Inc. Citation for this article: J. Clin. Invest. 117:2019-2027 (2007). doi:10.1172/JCI31942. most frequently affected site (occurring in $90 \%$ of cases), the disease can progress with loss of facial, eyebrow, and eyelash hair.

There is a tendency in the disease for dark hairs to be preferentially lost and white hairs spared. In fact, there are well documented case reports of "overnight graying" that have turned out to represent a diffuse variant of AA, where preexisting gray hair has been demasked by a fulminant attack of AA on darkly pigmented hair follicles alone (9). AA almost exclusively attacks growing (anagen) hair follicles that engage in active melanogenesis (10). These clinical and histological observations have encouraged the postulate that hair follicle melanocyte- and/or anagen-associated autoantigens play a key role in AA pathogenesis $(2,11)$.

$\mathrm{AA}$ is associated with autoimmune thyroiditis $(1,12)$ and vitiligo (autoimmune loss of melanocytes) (12), and males and females are affected equally (1). The lifetime risk of AA has been calculated as approximately $1.7 \%$, making it one of the most common autoimmune conditions (1).

In contrast to scarring hair loss induced by other chronic, inflammatory skin diseases, lesional hair follicles in AA generally do not scar and can regrow. Mild disease has a high rate of spontaneous remission, and even cases of severe AA universalis can spontaneously experience complete hair regrowth. Poor prognosis is associated with onset prior to puberty, extensive disease, a positive family history of AA, and atopy $(8,12,13)$. Positive family history is associated with early age of onset, and increased risk of thyroid disease is most evident in those patients with a family history of AA. Positive family history among first-degree relatives has been reported to be as high as $47 \%$ for patients with early onset, in contrast to $1.6 \%$ for all patients (14).

Treatment is problematic and often very frustrating. While mild disease, defined as limited circles of hair loss, shows a high rate of spontaneous hair regrowth and often responds to intralesional administration of corticosteroids, severe disease, such as AA totalis or universalis, shows an overall poor response to treatment. This problem is aggravated by the fact that generally accepted, strictly evidence-based medicine guidelines for AA management remain to be developed $(8,15)$. Immunotherapy with allergic contact sensitizers can be effective $(16,17)$. These sensitizers (e.g., diphenylcyclopropenone) are applied weekly in a concentration sufficient to achieve low-grade chronic dermatitis. Theories as to their 

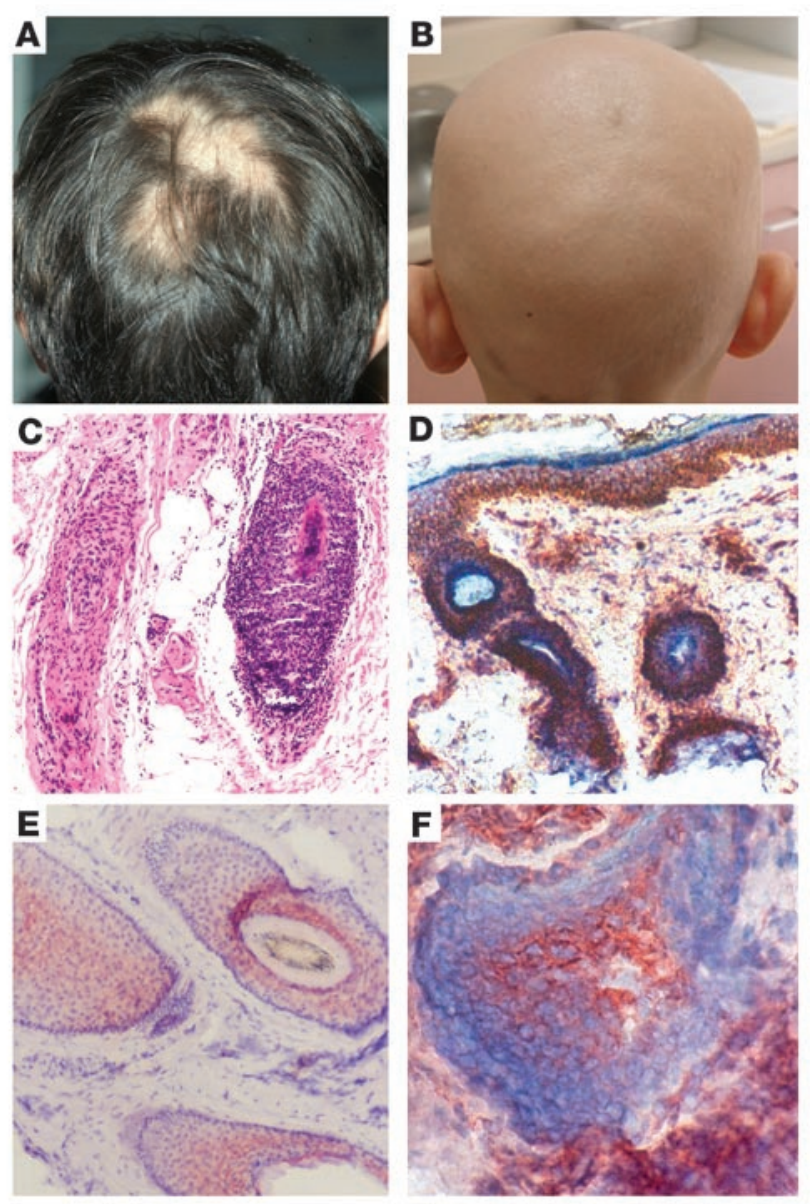

mechanism(s) of action include diversion of the $\mathrm{T}$ cell response from the hair follicle to the epidermis, interference with lymphocyte homing, induction of nonspecific, localized immunosuppression as a result of a chronic immune response, and production of immunosuppressive cytokines (e.g., TGF- $\beta$ and IL-10) $(18,19)$.

\section{Histologic features}

The key histologic feature of AA is a lymphocytic infiltrate around the lower hair follicle, which may appear in a characteristic "swarm of bees" pattern (Figures 1 and 2) (20). CD4 ${ }^{+} \mathrm{T}$ cells predominate in the infiltrate surrounding the hair follicle, while $\mathrm{T}$ cells within the follicular epithelium are predominantly $\mathrm{CD}^{+}$ (21). Since the perifollicular inflammatory cell infiltrate spares the bulge region of the hair follicle, which is the site of follicular epithelial stem cells, there is no scarring, and follicles retain the potential for regrowth.

Affected hair follicles terminate the anagen phase prematurely and regress via the induction of massive apoptosis of the lower portion of the follicle (catagen phase), resulting in a resting hair follicle (telogen phase). Hair follicles may then reenter the anagen phase, but in the presence of lymphocytic infiltrate, anagen is terminated prematurely, resulting in miniaturized hair follicles (22). AA represents a disorder of hair follicle cycling in a dual sense: it almost exclusively attacks anagen hair follicles and then greatly disturbs hair follicle cycling as such by "catapulting" anagen follicles into catagen $(10,11)$. Therefore, one potential

\section{Figure 1}

AA clinical presentation, histology, and immunohistochemistry. (A) AA and (B) AA totalis. (C-F) Histology of AA: features include perifollicular and intrafollicular infiltrate of lymphocytes as well as dystrophy of the hair follicle (C). Immunochemistry demonstrating follicular expression of HLA-A,B,C (Dako) (D), HLA-DR (Biodesign) (E), and CD54 (also known as ICAM-1; Biodesign) (F). Original magnification, $\times 80(\mathbf{C}-\mathbf{E}) ; \times 160(\mathbf{F})$.

therapy proposed to halt disease progression involves arresting hair follicles in the telogen stage of the hair cycle $(2,11)$.

\section{Genetics of AA}

There are two general approaches to investigating the genetic contributions to disease. In association studies, an individual suspect gene is tested for association with the condition. The concern with this approach is the possibility of false associations as a result of linkage disequilibrium. For this reason, it is necessary to repeat association studies in multiple populations. Recently, genome-wide searches have been utilized for identification of chromosomal regions associated with disease risk. This genomewide approach has the advantage that it is not biased by an initial hypothesis. However, identification of chromosomal regions with such genome-wide screens are only a first step, and much additional effort is required to map the risk to specific genes. An example of this approach is the mapping of vitiligo-associated multiple autoimmune disease to the NACHT leucin-rich-repeat protein 1 (NALP1) gene (23). NALP1 is involved in the innate immune response to pathogens. Identification of a regulator of the innate immune response as a mediator of autoimmune disease is a significant theoretical advance made possible by the nonbiased nature of the initial whole-genome screen.

As with most autoimmune diseases, AA exhibits HLA gene associations. Since HLA molecules present peptides to T cells, it has been proposed that HLA associations with autoimmunity may indicate more efficient presentation of cognate autoantigen by a particular HLA molecule (24). One recurrent finding between population groups is that $H L A-D Q B 1 * 03$ appears to be a general susceptibility gene $(25-28)$. HLA-DQB1*03 has been reported to be present in as many as $80 \%$ of AA patients in the United States (29). The association with $D Q B 1 * 03$ has been replicated in a Turkish population (30). A variety of additional HLA associations have been reported in multiple populations but await confirmation $(31,32)$. Certain HLA associations may provide relative protection from AA, as has been proposed for HLA-DRw52a (33) and HLA$D R B 1 * 03$ (34). Presumably a protective HLA allele would present autoantigen poorly, but that alone would not explain a dominant phenotype. It is possible that protection reflects preferential presentation of epitopes recognized by Tregs or linkage disequilibrium with other HLA-linked genes.

The non-classic MHC gene MHC class I chain-related major histocompatibility complex class I chain-related gene A $\left(M I C A\left({ }^{*}\right) 6\right)$ is also associated with AA (35). MICA is recognized by subsets of NK cells, which are activated by MICA interaction with the NK cell receptor NKG2D, suggesting a role for NK cells in AA pathogenesis. Lesional skin in AA patients demonstrates increased numbers of perifollicular of NK cells (36).

Down syndrome is associated with an increased incidence of AA (37). This finding now has a molecular basis following the identification of a gene of interest on chromosome 21 (38). Autoimmune 
polyendocrinopathy-candidiasis-ectodermal dystrophy (APECED) is an autosomal recessive syndrome consisting of mucocutaneous candidiasis with hypoparathyroidism or Addison disease. This syndrome is associated with multiple autoimmune disorders, including hypothyroidism, hypogonadism, insulin-dependent diabetes mellitus, chronic active hepatitis, pernicious anemia, vitiligo, biliary cirrhosis, and AA. The genetic basis is a mutation in the gene encoding autoimmune regulator (AIRE), mapping to 21q22.3 (39, 40 ). The risk of AA in patients with APECED is $30 \%$ and is associated with severe, early-onset disease (38). However, AIRE mutations are not associated with AA in the general population (41). Lymphoid-specific protein tyrosine phosphatase, non-receptor type 22 (PTPN22) is an additional immunoregulatory gene for which alleles are associated with AA (42).

Alleles of genes coding for cytokines, cytokine antagonists, and their receptors have also been associated with AA. These include polymorphisms in IL-1 receptor antagonists (43), macrophage migration inhibitory factor (MIF) (44), and Notch4, which maps to the MHC class II region (45). These polymorphisms are associated with early onset of more severe disease.

Most recently, a genome-wide search for linkage in 20 families with AA from the United States and Israel revealed evidence of at least four susceptibility loci on chromosomes 6, 10, 16, and 18 (46). This study was made possible by a registry of AA cases (47). Chromosome 6 exhibited two regions of disease association, one at $6 p$ that corresponds to the HLA locus, which is consistent with disease association studies. This human study is complemented by a genome-wide screen using the $\mathrm{C} 3 \mathrm{H} / \mathrm{HeJ}$ mouse model of AA (48). The strongest risk was associated with a region on murine chromosome 17, which corresponds to the MHC locus. Additional regions were identified on murine chromosomes 8, 9, and 15. Multiple genes of potential relevance to immune regulation, inflammation, hair pigmentation, and thyroid function were identified in the regions of interest. Genome-wide screens are obviously very powerful in that they are not biased by a previous hypothesis. However, it is necessary to follow-up with additional studies to map the risk regions to specific genes and confirm the findings in multiple population groups.

\section{Demonstration and dissection \\ of the immunopathogenesis of AA}

The association of AA with other autoimmune diseases and atopy is well recognized $(3,8,10,25)$, the characteristic perifollicular inflammatory infiltrate, the response to immunosuppressive or immunomodulatory therapy, and the HLA associations discussed above all have long made it intuitive that AA has an immunopathogenesis. Only recently, however, have the majority of AA experts accepted this distinct clinical entity as an organ-specific autoimmune disease.

\section{Hair follicle autoantibodies}

Grafting of hairless scalp from AA patients to nude mice results in dramatic regrowth of human hair (49). This was explained by the removal of immunologic influence from the hair follicles but does not distinguish whether a humoral or cellular immune pathogenesis underlies AA. Since antibodies directed to hair follicle-associated target proteins have been detected in patients with AA (50-52), some investigators have long favored the theory that AA results from a humoral autoimmune pathology. Circulating IgG antibodies in AA patients react with multiple components of anagen hair follicles $(50,52)$.
However, the basic questions remain whether these anti-hair follicle antibodies are pathogenic in vivo and whether they play a primary role in AA pathogenesis. Indeed, previous work has demonstrated failure of passive transfer of serum from human patients with AA to inhibit hair growth in human scalp skin grafted onto nude mice $(4,53)$. It is possible that the autoantibodies directed against follicular autoantigens are a marker for $\mathrm{CD}^{+} \mathrm{T}$ cell recognition without having a direct role in disease pathogenesis (3). Also it is conceivable that they play a role in secondary immune response cascades that may be triggered by the primary immunopathogenic events $(2,11)$ (Figure 3 ).

\section{Immune privilege collapse}

Perhaps the most intriguing features of the normal hair follicle immune system are the very low expression of MHC class I antigens and the absence of MHC class II antigen expression in the proximal (lower) epithelium of anagen hair follicles in all mammalian species investigated so far, including humans $(2,54-56)$. The mystery of why such an MHC class I-"low" tissue territory is not under constant attack by NK cells, which are primed to recognize and eliminate MHC class I- "low" virus-infected or transformed cells, may be explained by active suppression of NK cell functions by normal human anagen hair follicles (36). In the same region, the few Langerhans cells that are detectable are functionally impaired in their antigen-presenting capacity since they do not express MHC class II (56). Also, potent immunosuppressants such as TGF- $\beta 1$ and $\alpha$-melanocyte-stimulating hormone $(\alpha-\mathrm{MSH})$ are prominently expressed in the proximal anagen hair follicle $(2,57)$.

In addition to the absence of lymphatics, all these intriguing features of normal hair follicle immunology are classical characteristics of an anatomically defined tissue that is relatively immune privileged (2). Such tissues, of which the anterior eye chamber, testis, brain, and fetotrophoblast are the best studied examples, sequester auto- or alloantigens from immune recognition. Peripheral tolerance may also be induced against auto- and/or alloantigens that escape from such territories of relative immune privilege. For the maintenance of immune privilege and induction of peripheral tolerance, secreted factors such as TGF- $\beta 1, \alpha-M S H$, and IL-10 play a key role, and the number of mechanisms that are exploited by immunologically privileged tissues to suppress or evade undesired (auto-) immune responses is ever increasing (58-61). Recently, it has even been speculated that the rich endowment of the hair follicle's connective tissue sheath with mast cells may contribute to maintaining a low-level constitutive immune privilege of this skin appendage (62).

Long before any of this had been known, Billingham proposed that the anagen hair follicle represents a site of immune privilege (63). This resulted from his observation that transplanted allogeneic epidermal melanocytes can escape rejection by the host's immune system by seeking residence in the proximal anagen hair bulb. Subsequent phenomenological work has fully supported this hypothesis $(36,54-56)$, and though formal functional evidence supporting this hypothesis has yet to be reported, the anagen hair bulbs of humans and mice are now widely accepted to represent sites of relative immune privilege $(2,3)$.

Surprisingly, it took a long time until Billingham's visionary concept was applied to the pathogenesis of AA. In 1994 it was postulated that the immunoprivileged environment of the hair follicle serves to sequester melanogenesis- and/or other anagen-associated antigens from immune recognition and/or to induce periph- 


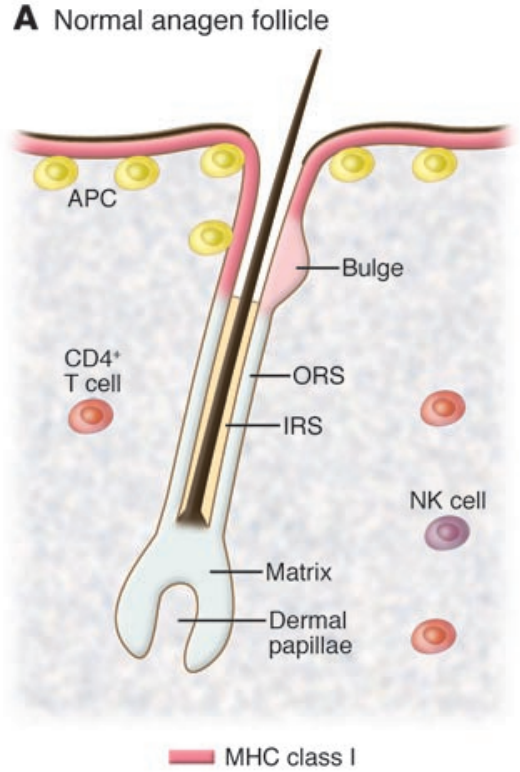

\section{Figure 2}

A model of immune privilege collapse in $A A$ pathogenesis. Both a normal anagen (growing) hair follicle $(\mathbf{A})$ and a hair follicle in $A A(B)$ are shown. MHC class I molecules are expressed on the epidermis, and on the most superficial (distal) portion of the normal hair follicle epithelium. The inferior (proximal) portions of the hair follicle are immune privileged and deficient in expression of MHC classes I and II as well as APCs. By contrast, the AA anagen hair follicle expresses MHC class I and II molecules throughout the follicular epithelium, including the portion adjacent to the dermal papilla of the hair follicle. Active AA also exhibits a perifollicular infiltrate of $\mathrm{CD}^{+}{ }^{+} \mathrm{T}$ cells and an intrafollicular infiltrate of CD8+ $\mathrm{T}$ cells. IRS, inner root sheath; ORS, outer root sheath. eral tolerance against such antigens (Figure 2) (11). It was further proposed that AA results from a collapse of hair follicle immune privilege and a $\mathrm{CD}^{+} \mathrm{T}$ cell-driven response to $\mathrm{MHC}$ class Ipresented autoantigens (11). The immune privilege collapse theory of AA pathogenesis postulated that the disease occurs only in those immunogenetically predisposed individuals in which four key events coincide (Figures 2 and 3): (a) breakdown of the MHC class I-based immune privilege of anagen hair follicles, triggered primarily by IFN- $\gamma$; (b) entry of the hair follicle into the anagen phase of the hair cycle, in which active melanogenesis occurs; (c) recognition by $\mathrm{CD}^{+} \mathrm{T}$ cells of autoantigens ectopically presented by MHC class I molecules in the anagen hair bulb; and (d) presence of costimulatory signals, $\mathrm{CD}^{+} \mathrm{T}$ cell help, and other activatory stimuli (e.g., dendritic cells) that launch an effective $\mathrm{CD}^{+} \mathrm{T}$ cellmediated attack on the anagen hair follicle epithelium $(2,11)$.

This basic hypothesis was later extended to account for a key role of locally generated immunosuppressants (e.g., $\alpha-M S H$, TGF- $\beta 1$, and IGF-1) (64) and NK cell-suppressing activities (e.g., MIF expression) (36) as "guardians" of hair follicle immune privilege, whose insufficient activity and/or function was thought to predispose individuals toward AA development, while immune privilege repair via these agents was suggested to underlie spontaneous AA remission and hair regrowth (2).

\section{Transfer of AA with T cells}

Grafting of human hairless (lesional) AA scalp to immunodeficient SCID mice results in hair regrowth similar to the results reported with nude mice. It is possible to prevent hair regrowth by injection of autologous lesional scalp T cells that have been activated by culture with homogenized hair follicles as a source of autoantigen, along with APCs (4). Importantly, autoantigen derived from hair follicles was essential for activation of $\mathrm{T}$ cells to induce hair loss. Scalp T cells activated by culture with IL-2 alone and the mitogen phytohemagglutinin were not effective. Neither were scalp T cells cultured with homogenized scalp skin depleted of hair follicles (65). Injection of properly activated $\mathrm{T}$ cells not only caused hair loss but induced expression of ICAM-1, HLA-DR, and HLA-A, -B, and -C on follicular epithelium. $\mathrm{CD} 4^{+} \mathrm{T}$ cells tended to be perifollicular, and $\mathrm{CD}^{+} \mathrm{T}$ cells were found to be intrafollicular, as is the case with the naturally occurring disease. IFN- $\gamma$ was expressed by $\mathrm{T}$ cells, and IFN- $\gamma$-inducible protein 10 (IP-10) was expressed by follicular epithelium (66). Though AA lesions can be induced by the transfer of $\mathrm{CD}^{+} \mathrm{T}$ cells alone, optimal induction of hair loss requires transfer of both $\mathrm{CD}^{+}$and $\mathrm{CD}^{+} \mathrm{T}$ cells (67). These experiments strongly support a role for $\mathrm{T}$ cells in the pathogenesis of $\mathrm{AA}$, with $\mathrm{CD} 8^{+} \mathrm{T}$ cells as the critical players. These data are perfectly in line with the immune privilege collapse hypothesis (Figure 3) $(2,3)$.

\section{Role of T cell-dependent melanocyte autoantigens in AA} Clinical observations have long suggested that melanocyte-associated autoantigens may be targets in $\operatorname{AA}(2,11)$. Active disease often preferentially results in loss of pigmented hair in patients who partially gray, and white hairs are frequently seen with initial regrowth. This observation is supported by ultrastructural evidence that hair bulb melanocytes are specifically damaged in acute AA, even before any damage is morphologically detectable in hair bulb keratinocytes (68). However, since autoantibodies to autologous melanocyte autoantigens were not detected in AA patients (69), a T cell-dependent mechanism was thought to be responsible. Melanocyte-associated peptides are capable of activating lesional $T$ cells to induce hair loss in human scalp grafts on SCID mice (70). HLA-A2-restricted melanocyte peptides were studied using grafts and $\mathrm{T}$ cells from HLA-A2-positive patients. The most consistent peptide autoantigens in this study were the Gp100-derived G9-209 and G9-280 peptides as well as melanoma antigen recognized by T cells 1 (MART-1). Multiple peptides were effective, suggesting that epitope spreading is likely to have a role in the broad nature of the anti-melanocyte response (70). Epitope spreading is the process whereby an autoimmune response directed against one epitope or autoantigen expands to recognize additional epitopes of the same protein or physically associated proteins.

\section{Additional insights from animal models}

The most extensively characterized and readily accessible AA model is the $\mathrm{C} 3 \mathrm{H} / \mathrm{HeJ}$ mouse. Female $\mathrm{C} 3 \mathrm{H} / \mathrm{HeJ}$ mice spontaneously develop AA, with approximately $20 \%$ prevalence at 6 months (48). 


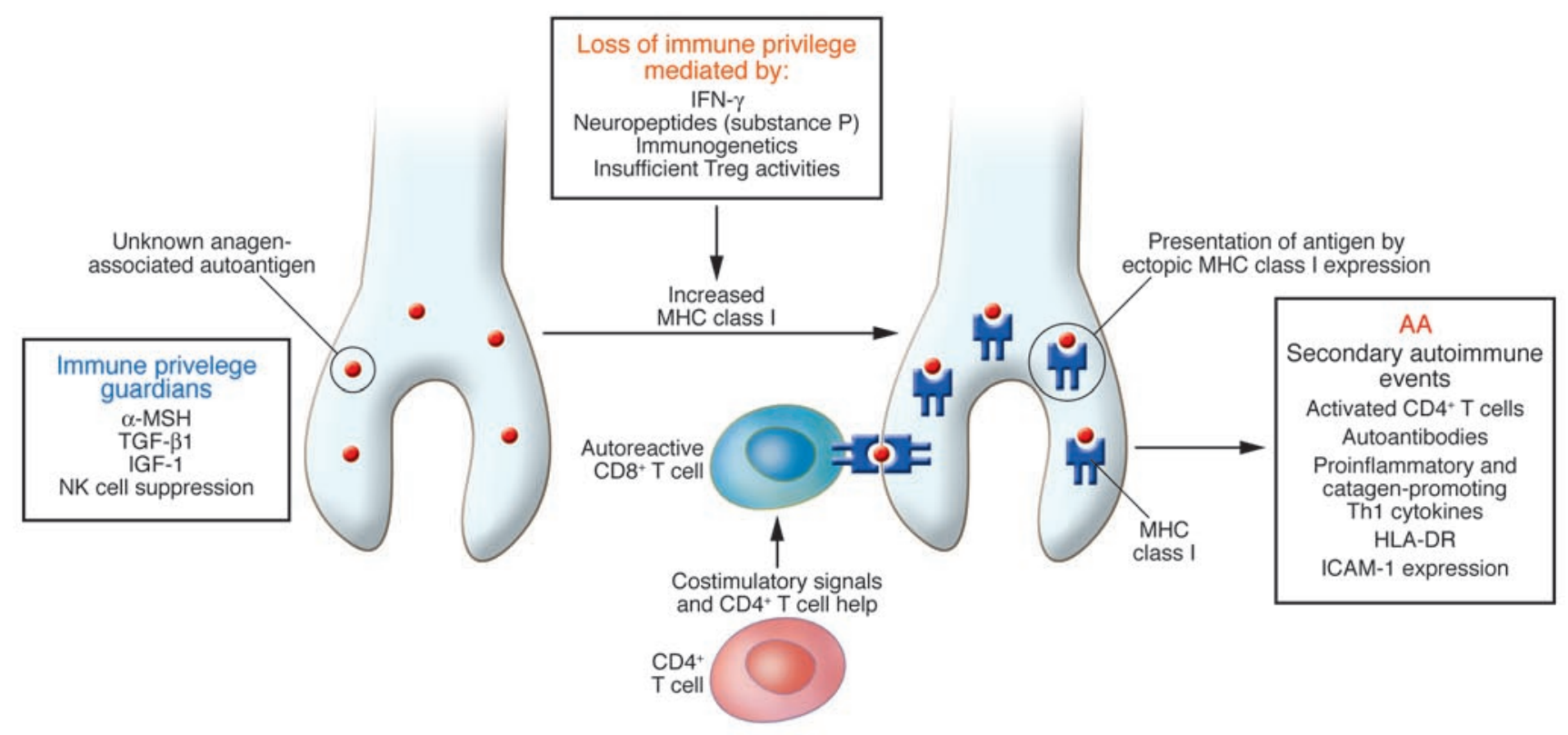

Figure 3

Proposed pathogenesis of AA. Cytokines and cellular factors responsible for maintaining immune privilege are listed in the left box. Those factors believed to mediate loss of immune privilege and initiation of disease are listed in the middle box. Loss of immune privilege is associated with expression of $\mathrm{MHC}$ class I molecules, which are capable of presenting hair follicle autoantigens to T lymphocytes. Secondary autoimmune amplification circuits that may help establish or amplify the pathology are listed in the right box.

Murine AA has a similar histology to the human disease, although the inflammatory cell infiltrate also extends to the distal follicle. Murine hair follicles express similar changes with loss of follicular immune privilege and ectopic expression of ICAM-1, MHC class I, and $\mathrm{MHC}$ class II. AA can be transferred to other $\mathrm{C} 3 \mathrm{H} / \mathrm{HeJ}$ mice by skin grafting (71). Transfer of the condition is dependent upon an intact immune response in the recipient mouse and requires both $\mathrm{CD}^{+}$and $\mathrm{CD}^{+} \mathrm{T}$ cells (72), in line with the human data using scalp grafts on SCID mice (67). The DEBR rat is another well established animal model of a spontaneously arising disease that is similar to AA $(73,74)$. Depletion of either $\mathrm{CD}^{+}$or $\mathrm{CD} 4^{+} \mathrm{T}$ cells results in complete hair regrowth in this rat model $(75,76)$.

The role of lymphocyte homing in AA has been explored using the $\mathrm{C} 3 \mathrm{H} / \mathrm{HeJ}$ model. Monoclonal antibody against CD44v10, commonly expressed on activated lymphocytes, blocks development of AA (77). Inhibition of AA onset has also been demonstrated using monoclonal antibodies against B7 costimulatory antigens commonly expressed on APCs (77). Inflammatory T cells in AA are cytotoxic and possess both the granzyme $\mathrm{B}$ and Fas/Fas ligand (Fas/FasL) cytotoxic mechanisms (78). C3H/HeJ mice deficient in Fas or FasL are not susceptible to AA (79). This resistance is localized to the hair follicle because Fas- or FasL-deficient skin transplanted to AA-affected mice continues to produce hair. It was proposed on this basis that Fas/FasL interactions play an important role in AA pathogenesis $(77,79)$. However, since hardly any relevant Fas/FasL proteins are expressed in normal human scalp skin (56), it remains unclear whether Fas/FasL interactions play any role in human AA pathogenesis.

The identification and characterization of dysfunctional Tregs in several different human diseases including psoriasis, multiple sclerosis, and autoimmune polyglandular syndrome type 1 sug- gests that their normal function may be important in preventing autoimmune disease (80-82). $\mathrm{C} 3 \mathrm{H} / \mathrm{HeJ}$ mice with AA have a low level of $\mathrm{CD}^{+} \mathrm{CD} 25^{+}$Treg cells in the skin (83). Injection of $\mathrm{CD} 4^{+} \mathrm{CD} 25^{+}$Treg cells to $\mathrm{C} 3 \mathrm{H} / \mathrm{HeJ}$ mice inhibits the induction of $\mathrm{AA}$ by $\mathrm{CD} 4^{+} \mathrm{CD} 25^{-} \mathrm{T}$ cells and also prevents $\mathrm{CD} 8^{+} \mathrm{T}$ cell-induced localized hair loss. Mice receiving $\mathrm{CD} 4^{+} \mathrm{CD} 25^{+}$Tregs do not develop AA and expressed remarkably high levels of the antiinflammatory cytokine IL-10. Therefore, it is indeed conceivable that insufficient Treg activities contribute to the pathogenesis of AA (Figure 3 ) and that the upregulation of desired Treg activities deserves careful exploration as a target in future AA management.

\section{Microarray studies}

Microarray analysis of mRNA transcription in involved versus uninvolved skin has been performed both from human scalp biopsies and $\mathrm{C} 3 \mathrm{H} / \mathrm{HeJ}$ mice (84). Involved skin of mice demonstrates increased mRNA for a multitude of immune-associated genes including those encoding MHC molecules, adhesion molecules, complement components, immunoglobulin genes, antigen processing proteins, and lymphocyte markers (e.g., CD3). Involved human skin demonstrates increased mRNA for granzyme A, STAT1, as well as a variety of cytokines, and cytokine receptors. Transcripts downregulated in humans and mice include hair keratins. The data reflects a large influx of inflammatory cells, which confounds the analysis of changes in hair follicle gene transcription.

\section{IFN- $\gamma$ in AA: the match that lights the fire?}

Several lines of evidence support a Th1 cytokine bias in the pathogenesis of AA. Follicular expression of HLA-DR is indirect evidence for IFN- $\gamma$ production, as IFN- $\gamma$ appears to be unique in inducing MHC classes I and II in the lower part of the follicular epithelium 


\title{
Major challenges for clinically relevant AA research
}

\author{
Challenge \\ Identify genetic factors that determine disease susceptibility, severity, progression and/or response to therapy \\ HLA associations, cytokine alleles, other immune response genes \\ Constitutively high MHC class I expression level in anagen hair bulb \\ Constitutively inefficient suppression of perifollicular NK cell activities \\ Constitutively ineffective "immune privilege guardian" system (e.g., low intrafollicular expression/activity \\ of $\alpha$-MSH, TGF- $\beta 1$, IGF- 1 , and/or cognate receptors) \\ Inappropriate tendency to secrete potent MHC class I expression stimulators (e.g., IFN- $\gamma$, substance P) \\ Genetically determined tendency toward massive secondary inflammatory damage once immune privilege collapse \\ has occurred (which is the role of innate immunity, CD44, costimulatory signals, cytokine and cytokine receptor \\ alleles, autoantibodies, $\mathrm{CD}^{+}{ }^{+} \mathrm{T}$ cell activities, etc.) \\ Identify and neutralize key inducers of immune privilege collapse \\ IFN- $\gamma$ \\ Substance P \\ Other inducers not yet identified \\ Therapeutically administer recognized MHC class I downregulators \\ $\alpha-\mathrm{MSH}$ receptor agonists \\ TGF- $\beta 1$ \\ IGF-1 \\ Tacrolimus \\ In severe cases, manipulate hair follicle cycling to halt AA progression \\ Arrest hair follicles in telogen phase to render them nonsusceptible to immune attack \\ Identify the elusive AA autoantigen \\ Hair follicle melanocyte-associated autoantigen(s)? \\ Anagen-associated (keratinocyte) autoantigen(s)? \\ Once autoantigens are identified, induce peripheral tolerance or immune deviation \\ Induction of Tregs \\ Interference with costimulation and APCs \\ Switch from Th1 to Th2 response, use of cytokines (e.g., IL-10)
}

(85-87). Induction of hair loss in the human scalp graft/SCID mouse system is associated with T cell IFN- $\gamma$ expression and follicular expression of IP-10 (66). Hair regrowth in scalp grafts is associated with IL-10 expression. Additional evidence for a Th1 bias is derived from the $\mathrm{C} 3 \mathrm{H} / \mathrm{HeJ}$ mouse model. IFN- $\gamma$-deficient mice are resistant to the development of AA (6), and mice with a relative deficiency of IL-2 expression develop AA less frequently (88). In fact, low-dose IFN- $\gamma$ can be exploited experimentally to induce immune privilege collapse of normal human anagen hair follicles in vitro, likely via IFN regulatory factor 1 -mediated mechanism (64). Given that higher doses of IFN- $\gamma$ also act as a potent catagen inducer in human scalp hair follicles (89), this Th1 cytokine is a prime candidate to be the "match that lights the fire" early during AA immunopathogenesis (Figure 3).

The ability of IFN- $\gamma$ to induce ectopic expression of follicular MHC classes I and II in normal murine hair follicle epithelium was used to test the hypothesis that AA results from loss of immune privilege. $\mathrm{C} 3 \mathrm{H} / \mathrm{HeJ}$ female mice were injected intravenously with IFN- $\gamma$ to induce follicular MHC. These mice demonstrated an increased rate of development of AA (90). This is in line with both the immune privilege collapse hypothesis and the finding that IFN- $\gamma$-deficient mice are resistant to AA (6). However, only genetically susceptible $\mathrm{C} 3 \mathrm{H} / \mathrm{HeJ}$ mice exhibited AA following this treatment, demonstrat- ing that loss of immune privilege alone is insufficient for induction of autoimmune hair loss in AA, just as originally proposed (11).

\section{AA and stress: the neuroendocrine-immune hypothesis}

Anecdotal reports have long suggested a connection between the triggering or aggravation of AA and acute or chronic psychoemotional stress (8). While this likely is of relevance only in a small minority of AA patients, increasing insight into the importance of the brain-skin connection, e.g., in the control of cutaneous neurogenic inflammation (91-96), encourages one to consider the potential impact of neuroendocrine factors on AA. Murine stress models demonstrate nerve growth factor (NGF)-, substance P-, and mast cell-dependent inhibitory effects of stress on hair growth (93-96). In mice, stress-induced upregulation of NGF seems to stimulate substance P synthesis in dorsal root ganglia and prematurely induces catagen development (92-95). Transport of this stress-associated neuropeptide via peptidergic sensory nerve fibers into the skin leads to mast cell-dependent, perifollicular neurogenic inflammation, which in turn causes hair growth inhibition and premature catagen induction. In addition, NGF alone can prematurely induce catagen development (92-95).

Interestingly, the prototypic stress-associated neuropeptide substance P also can induce a collapse of MHC class I-based hair 


\section{science in medicine}

follicle immune privilege in organ-cultured normal human scalp hair follicles (97). Substance P is increased in early AA lesions in mice, and $\mathrm{CD}^{+} \mathrm{T}$ cells express neurokinin- 1 receptor, which mediates substance $\mathrm{P}$ action (98). Treatment of mice with substance $\mathrm{P}$ results both in mast cell degranulation and hair follicle degeneration (catagen), associated with an increase in the number of $\mathrm{CD}^{+}$ granzyme $\mathrm{B}^{+} \mathrm{T}$ cells (98). The observation that lesional AA skin in humans shows abnormalities in sensory peptidergic innervation $(96,99)$ suggests that the neuroendocrine-immune connection in $\mathrm{AA}$, and its modulation by stress, deserves additional research.

\section{Conclusions and perspectives}

AA deserves to be fully exploited as a highly instructive model for organ-specific, T cell-dependent autoimmunity. There is evidence of a strong immunogenetic component to the disease in both humans and mice, with linkage to MHC, as well as cytokine alleles. Induction of AA is associated with collapse of hair follicle immune privilege, in which neurogenic inflammation might play a role, at least in some cases of AA. It is hypothesized that neurogenic inflammation has a role in this loss of immune privilege. It is possible to induce AA in genetically susceptible mice by abrogating hair follicle immune privilege, for which IFN- $\gamma$ operates as key destroyer of hair follicle immune privilege in mice and man. This disease-promoting effect of IFN- $\gamma$ may be counterbalanced by locally generated guardians of hair follicle immune privilege such as TGF- $\beta 1, \alpha-\mathrm{MSH}$, and IL-10. Mice not genetically susceptible to AA do not experience hair loss with abrogation of immune privilege, underscoring the complex interplay between genetics and loss of tolerance in the initiation of autoimmunity. Subsequent pathology appears to be mediated by a predominantly CD8-driven, Th1-type T cell responses, in which such downstream apoptotic mediators as Fas/FasL interactions and granzyme B may be involved, at least in mice.

Unresolved issues in pathogenesis include the role of hair follicle autoantibodies, which are reproducibly detectable in patients with
AA (50-52). The potential role of the innate immune system needs to be investigated in view of identification of a gene regulating innate immunity (NALP1) in vitiligo (23). The role of Tregs also requires additional investigation (83).

Reestablishment of immune privilege has been proposed as a therapeutic manipulation to reverse disease and prevent disease progression $(2,11)$. Cytokines that have been shown to function in maintaining and restoring human hair follicle immune privilege, such as TGF- $\beta, \alpha-M S H$, and IL-10, and clinically widely employed immunophilin ligands such as FK 506 are interesting candidates for this novel therapeutic approach (Figure 3) (64). "Major challenges for clinically relevant AA research" summarizes our perspective on the key challenges that we must meet in order to offer our patients more effective therapy. The $\mathrm{C} 3 \mathrm{H} / \mathrm{HeJ}$ murine model shows promise as a screening tool for such novel therapies $(100,101)$.

AA offers many benefits as a model for the study of autoimmunity, in that it can be used to dissect the contributing roles of immune privilege, immunogenetics, and neuroendocrine factors in the initiation and propagation of autoimmune disease. More systematic and widespread exploitation of this autoimmunity model in the immunology community, therefore, will not only further promote our understanding of AA pathogenesis and the development of better AA management strategies but will also be widely relevant to the general study of autoimmunity.

Address correspondence to: Richard S. Kalish, Department of Dermatology, Stony Brook University, Stony Brook, New York 117948165, USA. Phone: (631) 444-7681; Fax: (631) 444-3844; E-mail: richard.kalish@stonybrook.edu. Or to: Amos Gilhar, Skin Research Laboratory, The Ruth and Bruce Rappaport Faculty of Medicine, Technion-Israel Institute of Technology, Efron St. 1, PO Box 9649 Bat Galim, Haifa 31096, Israel. Phone: 972-4-8307091; Fax: 972-48307194; E-mail: amos.gilhar@flim.health.gov.il.
1. Safavi, K.H., Muller, S.A., Suman, V.J., Moshell, A.N., and Melton, L.J., 3rd. 1995. Incidence of alopecia areata in Olmsted County, Minnesota, 1975 through 1989. Mayo Clin. Proc. 70:628-633

2. Paus, R., Nickoloff, B.J., and Ito, T. 2005. A "hairy" privilege. Trends Immunol. 26:32-40.

3. Gilhar, A., and Kalish, R.S. 2006. Alopecia areata: a tissue specific autoimmune disease of the hair follicle. Autoimmun. Rev. 5:64-69.

4. Gilhar, A., Ullmann, Y., Berkutzki, T., Assy, B., and Kalish, R.S. 1998. Autoimmune hair loss (alopecia areata) transferred by T lymphocytes to human scalp explants on SCID mice. J. Clin. Invest. 101:62-67.

5. Sundberg, J.P., and King, L.E., Jr. 2003. Mouse alopecia areata models: an array of data on mechanisms and genetics. J. Investig. Dermatol. Symp. Proc. 8:173-175.

6. Freyschmidt-Paul, P., et al. 2006. Interferon-gamma deficient mice are resistant to the development of alopecia areata. Br. J. Dermatol. 155:515-521.

7. Ito, T., et al. 2005. Immunology of the human nail apparatus: the nail matrix is a site of relative immune privilege. J. Invest. Dermatol. 125:1139-1148.

8. Wasserman, D., Guzman-Sanchez, D.A., Scott, K., and McMichael, A. 2007. Alopecia areata. Int. J. Dermatol. 46:121-131.

9. Plinck, E.P., Peereboom-Wynia, J.D., Vuzevski, V.D., Westerhof, W., and Stolz, E. 1993. Turning white overnight, is it possible? [In Dutch]. Ned. Tijdschr. Geneeskd. 137:1207-1210.

10. McDonagh, A.J., and Messenger, A.G. 1996. The pathogenesis of alopecia areata. Dermatol. Clin. 14:661-670.
11. Paus, R., Slominski, A., and Czarnetzki, B.M. 1994. Is alopecia areata an autoimmune-response against melanogenesis-related proteins, exposed by abnormal MHC class I expression in the anagen hair bulb? Yale J. Biol. Med. 66:541-554.

12. Tan, E., Tay, Y.K., Goh, C.L., and Chin Giam, Y. 2002. The pattern and profile of alopecia areata in Singapore - a study of 219 Asians. Int. J. Dermatol. 41:748-753.

13. Tosti, A., Bellavista, S., and Iorizzo, M. 2006. Alopecia areata: a long term follow-up study of 191 patients. J. Am. Acad. Dermatol. 55:438-441.

14. Yang, S., et al. 2004. The genetic epidemiology of alopecia areata in China. Br. J. Dermatol. 151:16-23.

15. Sladden, M.J., MacDonald Hull, S.P., Wood, M.L., Hutchinson, P.E., and Messenger, A.G. 2005. Alopecia areata: the need for guidelines and evidencebased dermatology. Br. J. Dermatol. 152:1086-1087.

16. Happle, R. 2002. Diphencyprone for the treatment of alopecia areata: more data and new aspects. Arch. Dermatol. 138:112-123.

17. Cotellessa, C., Peris, K., Caracciolo, E., Mordenti, C., and Chimenti, S. 2001. The use of topical diphenylcyclopropenone for the treatment of extensive alopecia areata. J. Am. Acad. Dermatol. 44:73-76.

18. Hoffmann, R., et al. 1996. Growth factor mRNA levels in alopecia areata before and after treatment with the contact allergen diphenylcyclopropenone. Acta Derm. Venereol. 76:17-20.

19. Gupta, P., et al. 2006. A chronic contact eczema impedes migration of antigen-presenting cells in alopecia areata. J. Invest. Dermatol. 126:1559-1573.

20. Sperling, L.C., and Lupton, G.P. 1995. Histopa- thology of nonscarring alopecia. J. Cutan. Pathol. 22:97-114.

21. Todes-Taylor, N., Turner, R., Wood, G.S., Stratte, P.T., and Morhenn, V.B. 1984. T cell subpopulations in alopecia areata. J. Am. Acad. Dermatol. 11:216-223.

22. Whiting, D.A. 2003. Histopathologic features of alopecia areata: a new look. Arch. Dermatol. 139:1555-1559.

23. Ying, J., et al. 2007. NALP1 in vitiligo-associated multiple autoimmune disease. N. Engl. J. Med. 356:1216-1225.

24. Sonderstrup, G., and McDevitt, H.O. 2001. DR, $\mathrm{DQ}$, and you: MHC alleles and autoimmunity. J. Clin. Invest. 107:795-796.

25. McDonagh, A.J., and Tazi-Ahnini, R. 2002. Epidemiology and genetics of alopecia areata. Clin. Exp. Dermatol. 27:405-409.

26. Colombe, B.W., Price, V.H., Khoury, E.L., Garovoy, M.R., and Lou, C.D. 1995. HLA class II antigen associations help to define two types of alopecia areata. J. Am. Acad. Dermatol. 33:757-764.

27. de Andrade, M., et al. 1999. Alopecia areata in families: association with the HLA locus. J. Investig. Dermatol. Symp. Proc. 4:220-223.

28. Marques Da Costa, C., et al. 2006. Earlier occurrence of severe alopecia areata in HLA-DRB $1 * 11$ positive patients. Dermatology. 213:12-14.

29. Colombe, B.W., Lou, C.D., and Price, V.H. 1999. The genetic basis of alopecia areata: HLA associations with patchy alopecia areata versus alopecia totalis and alopecia universalis. J. Investig. Dermatol. Symp. Proc. 4:216-219. 
30. Akar, A., Orkunoglu, E., Sengul, A., Ozata, M., and Gur, A.R. 2002. HLA class II alleles in patients with alopecia areata. Eur. J. Dermatol. 12:236-239.

31. Xiao, F.L., et al. 2005. Association of HLA-DQA1 and DQB1 alleles with alolpecia areata in Chinese Hans. Arch. Dermatol. Res. 297:201-209.

32. Xiao, F.L., et al. 2006. Association of HLA class I alleles with aloplecia areata in Chinese Hans. J. Dermatol. Sci. 41:109-119.

33. Duvic, M., et al. 1991. HLA-D locus associations in alopecia areata. DRw52a may confer disease resistance. Arch. Dermatol. 127:64-68.

34. Broniarczyk-Dyla, G., et al. 2002. The protective role of the HLA-DR locus in patients with various clinical types of alopecia areata. Arch. Immunol. Ther. Exp. (Warsz.). 50:333-336.

35. Barahmani, N., de Andrade, M., Slusser, J.P., Zhang, Q., and Duvic, M. 2006. Major histocompatibility complex class I chain-related gene A polymorphisms and extended haplotypes are associated with familial alopecia areata. J. Invest. Dermatol. 126:74-78

36. Ito, T., Saathoff, M., Nickoloff, B.J., Takigawa, M., and Paus, R. 2005. Novel aspects of hair follicle immune privilege and their relevance to alopecia areata [abstract]. J. Invest. Dermatol. 124(Suppl.):A103.

37. Schepis, C., Barone, C., Siragusa, M., Pettinato, R., and Romano, C. 2002. An updated survey on skin conditions in Down syndrome. Dermatology. 205:234-238

38. Tazi-Ahnini, R., et al. 2002. Role of the autoimmune regulator (AIRE) gene in alopecia areata: strong association of a potentially functional AIRE polymorphism with alopecia universalis. Tissue Antigens. 60:489-495.

39. Buzi, F., et al. 2003. Autoimmune polyendocrinopathy-candidiasis-ectodermal dystrophy syndrome: time to review diagnostic criteria? J. Clin. Endocrinol. Metab. 88:3146-3148.

40. Collins, S.M., Dominguez, M., Ilmarinen, T., Costigan, C., and Irvine, A.D. 2006. Dermatological manifestations of autoimmune polyendocrinopathy-candidiasis-ectodermal dystrophy syndrome. Br. J. Dermatol. 154:1088-1093.

41. Pforr, J., et al. 2006. Investigation of the p.Ser278Arg polymorphism of the autoimmune regulator (AIRE) gene in alopecia areata. Tissue Antigens. 68:58-61.

42. Kemp, E.H., et al. 2006. The non-synonymous C1858T substitution in the PTPN22 gene is associated with susceptibility to the severe forms of alopecia areata. Hum. Immunol. 67:535-539.

43. Tazi-Ahnini, R., et al. 2002. Genetic analysis of the interleukin1 receptor antagonist and its homologue IL1L1 in alopecia areata: strong severity association and possible gene interaction. Eur. J. Immunogenet. 29:25-30.

44. Shimizu, T., et al. 2005. Promoter region polymorphism of macrophage migration inhibitory factor is strong risk factor for young onset of extensive alopecia areata. Genes Immun. 6:285-289.

45. Tazi-Ahnini, R., et al. 2003. Notch4, a non-HLA gene in the MHC is strongly associated with the most severe form of alopecia areata. Hum. Genet. 112:400-403

46. Martinez-Mir, A., et al. 2007. Genomewide scan for linkage reveals evidence of several susceptibility Loci for alopecia areata. Am. J. Hum. Genet. 80:316-328.

47. Duvic, M., Norris, D., Christiano, A., Hordinsky, M., and Price, V. 2003. Alopecia areata registry: an overview. I. Investig. Dermatol. Symp. Proc. 8:219-221.

48. Sundberg, J.P., Silva, K.A., Li, R., Cox, G.A., and King, L.E. 2004. Adult-onset alopecia areata is a complex polygenic trait in the $\mathrm{C} 3 \mathrm{H} / \mathrm{HeJ}$ mouse model. J. Invest. Dermatol. 123:294-297.

49. Gilhar, A., and Krueger, G.G. 1987. Hair growth in scalp grafts from patients with alopecia areata and alopecia universalis grafted onto nude mice. Arch.
Dermatol. 123:44-50.

50. Tobin, D.J., Hann, S.K., Song, M.S., and Bystryn, J.C. 1997. Hair follicle structures targeted by antibodies in patients with alopecia areata. Arch. Dermatol. 133:57-61.

51. Tobin, D.J. 2003. Characterization of hair follicle antigens targeted by the anti-hair follicle immune response. J. Investig. Dermatol. Symp. Proc. 8:176-181.

52. Okamoto, M., et al. 2004. Autoantibodies to DFS70/LEDGF are increased in alopecia areata patients. J. Autoimmun. 23:257-266.

53. Gilhar, A., Pillar, T., Assy, B., and David, M. 1992. Failure of passive transfer of serum from patients with alopecia areata and alopecia universalis to inhibit hair growth in transplants of human scalp skin grafted on to nude mice. Br. J. Dermatol. 126:166-171.

54. Harrist, T.J., Ruiter, D.J., Mihm, M.C., and Bhan, A.K. 1983. Distribution of major histocompatibility antigens in normal skin. $\mathrm{Br}$. J. Dermatol. 109:623-633.

55. Paus, R., et al. 1998. Generation and cyclic remodeling of the hair follicle immune system in mice. J. Invest. Dermatol. 111:7-18.

56. Christoph, T., et al. 2000. The human hair follicle immune system: cellular composition and immune privilege. Br. J. Dermatol. 142:862-873.

57. Paus, R., Christoph, T., and Muller-Rover, S. 1999. Immunology of the hair follicle: a short journey into terra incognita. J. Investig. Dermatol. Symp. Proc 4:226-234.

58. Niederkorn, J.Y. 2006. See no evil, hear no evil, do no evil: the lessons of immune privilege. Nat. Immu nol. 7:354-359.

59. Cobbold, S.P., et al. 2006. Immune privilege induced by regulatory $\mathrm{T}$ cells in transplantation tolerance. Immunol. Rev. 213:239-355.

60. Simpson, E. 2006. A historical perspective on immunological privilege. Immunol. Rev. 213:12-22.

61. Wahl, S.M., Wen, J., and Moutsopoulos, N. 2006. TGF-beta: a mobile purveyor of immune privilege. Immunol. Rev. 213:213-227.

62. Waldmann, H. 2006. Immunology: protection and privilege. Nature. 442:987-988.

63. Billingham, R.E., and Silvers, W.K. 1971. A biologist's reflections on dermatology. J. Invest. Dermatol. 57:227-240.

64. Ito, T., et al. 2004. Collapse and restoration of MHC class-I-dependent immune privilege: exploiting the human hair follicle as a model. Am. J. Pathol. 164:623-634.

65. Gilhar, A., Shalaginov, R., Assy, B., Serafimovich, S. and Kalish, R.S. 1999. Alopecia areata is a T-lymphocyte mediated autoimmune disease: lesional human T-lymphocytes transfer alopecia areata to human skin grafts on SCID mice. J. Investig. Dermatol. Symp. Proc. 4:207-210.

66. Gilhar, A., et al. 2003. Transfer of alopecia areata in the human scalp graft/Prkdcscid (SCID) mouse system is characterized by a TH1 response. Clin. Immunol. 106:181-187.

67. Gilhar, A., et al. 2002. Alopecia areata is mediated by cooperation between CD4+ and CD8+ T-lymphocytes: transfer to human scalp explants on Prkdcscid mice. Arch. Dermatol. 138:916-922.

68. Tobin, D.J., Fenton, D.A., and Kendall, M.D. 1990 Ultrastructural observations on the hair bulb melanocytes and melanosomes in acute alopecia areata. J. Invest. Dermatol. 94:803-807.

69. Khoury, E.L., and Price, V.H. 1995. No cell-surfacereactive antibodies against cultured autologous melanocytes found in alopecia areata sera. J. Invest. Dermatol. 104(5 Suppl.):24S-25S.

70. Gilhar, A., et al. 2001. Melanocyte-associated T cell epitopes can function as autoantigens for transfer of alopecia areata to human scalp explants on Prkdc(scid) mice. J. Invest. Dermatol. 117:1357-1362. 71. McElwee, K.J., Boggess, D., King, L.E., Jr., and Sund- berg, J.P. 1998. Experimental induction of alopecia areata-like hair loss in $\mathrm{C} 3 \mathrm{H} / \mathrm{HeJ}$ mice using full-thickness skin grafts. J. Invest. Dermatol. 111:797-803.

72. McElwee, K.J., et al. 2002. Resistance to alopecia areata in $\mathrm{C} 3 \mathrm{H} / \mathrm{HeJ}$ mice is associated with increased expression of regulatory cytokines and a failure to recruit CD4+ and CD8+ cells. J. Invest. Dermatol. 119:1426-1433.

73. Michie, H.J., Jahoda, C.A., Oliver, R.F., and Johnson, B.E. 1991. The DEBR rat: an animal model of human alopecia areata. Br. J. Dermatol. 125:94-100.

74. Oliver, R.F., and Lowe, J.G. 1995. Oral cyclosporin A restores hair growth in the DEBR rat model for alopecia areata. Clin. Exp. Dermatol. 20:127-131.

75. McElwee, K.J., Pickett, P., and Oliver, R.F. 1996. The DEBR rat, alopecia areata and autoantibodies to the hair follicle. Br. J. Dermatol. 134:55-63.

76. McElwee, K.J., Spiers, E.M., and Oliver, R.F. 1999. Partial restoration of hair growth in the DEBR model for alopecia areata after in vivo depletion of CD4+ T cells. Br. J. Dermatol. 140:432-437.

77. Freyschmidt-Paul, P., et al. 2000. Treatment with an anti-CD44v10-specific antibody inhibits the onset of alopecia areata in $\mathrm{C} 3 \mathrm{H} / \mathrm{HeJ}$ mice. J. Invest. Dermatol. 115:653-657.

78. Bodemer, C., et al. 2000. Role of cytotoxic T cells in chronic alopecia areata. J. Invest. Dermatol. 114:112-116.

79. Freyschmidt-Paul, P., et al. 2003. Fas-deficient C3.MRL-Tnfrsf6(lpr) mice and Fas ligand-deficient $\mathrm{C} 3 \mathrm{H} / \mathrm{HeJ}-\mathrm{Tnfsf} 6$ (gld) mice are relatively resistant to the induction of alopecia areata by grafting of alopecia areata-affected skin from $\mathrm{C} 3 \mathrm{H} / \mathrm{HeJ}$ mice. J. Investig. Dermatol. Symp. Proc. 8:104-108.

80. Sugiyama, H., et al. 2005. Dysfunctional blood and target tissue $\mathrm{CD} 4+\mathrm{CD} 25$ high regulatory $\mathrm{T}$ cells in psoriasis: mechanism underlying unrestrained pathogenic effector T cell proliferation. J. Immunol. 174:164-173.

81. Viglietta, V., Baecher-Allan, C., Weiner, H.L., and Hafler, D.A. 2004. Loss of functional suppression by CD4+CD25+ regulatory $\mathrm{T}$ cells in patients with multiple sclerosis. J. Exp. Med. 199:971-979.

82. Kriegel, M.A., et al. 2004. Defective suppressor function of human CD4+CD25+ regulatory T cells in autoimmune polyglandular syndrome type II. J. Exp. Med. 199:1285-1291.

83. Zöller, M., McElwee, K.J., Engel, P., and Hoffmann, R. 2002. Transient CD44 variant isoform expression and reduction in $\mathrm{CD} 4(+) / \mathrm{CD} 25(+)$ regulatory $\mathrm{T}$ cells in $\mathrm{C} 3 \mathrm{H} / \mathrm{HeJ}$ mice with alopecia areata. J. Invest. Dermatol. 118:983-992.

84. Carroll, J.M., McElwee, K.J., King, L.E., Byrne, M.C., and Sundberg, J.P. 2002. Gene array profiling and immunomodulation studies define a cell-mediated immune response underlying the pathogenesis of alopecia areata in a mouse model and humans. J. Invest. Dermatol. 119:392-402.

85. Gilhar, A., Etzioni, A., Assy, B., and Eidelman, S. 1993. Response of grafts from patients with alopecia areata transplanted onto nude mice, to administration of interferon-gamma. Clin. Immunol. Immunopathol. 66:120-126.

86. Konig, A., Happle, R., and Hoffmann, R. 1997. IFN-gamma-induced HLA-DR but not ICAM-1 expression on cultured dermal papilla cells is downregulated by TNF-alpha. Arch. Dermatol. Res. 289:466-470.

87. Ruckert, R., Hofmann, U., van der Veen, C., Bulfone-Paus, S., and Paus, R. 1998. MHC class I expression in murine skin: developmentally controlled and strikingly restricted intraepithelial expression during hair follicle morphogenesis and cycling, and response to cytokine treatment in vivo. J. Invest. Dermatol. 111:25-30.

88. Freyschmidt-Paul, P., et al. 2005. Reduced expression of interleukin-2 decreases the frequency of alopecia areata onset in $\mathrm{C} 3 \mathrm{H} / \mathrm{HeJ}$ mice. J. Invest. 
Dermatol. 125:945-951.

89. Ito, T., et al. 2005. Interferon-gamma is a potent inducer of catagen-like changes in cultured human anagen hair follicles. Br. J. Dermatol. 152:623-631.

90. Gilhar, A., Kam, Y., Assy, B., and Kalish, R.S. 2005 Alopecia areata induced in $\mathrm{C} 3 \mathrm{H} / \mathrm{HeJ}$ mice by interferon-gamma: evidence for loss of immune privilege. J. Invest. Dermatol. 124:288-289.

91. Paus, R., Theoharides, T.C., and Arck, P.C. 2006. Neuroimmunoendocrine circuitry of the 'brainskin connection'. Trends Immunol. 27:32-39.

92. Peters, E.M., Arck, P.C., and Paus, R. 2006. Hair growth inhibition by psychoemotional stress: a mouse model for neural mechanisms in hair growth control. Exp. Dermatol. 15:1-13.

93. Arck, P.C., et al. 2005. Mast cell deficient and neurokinin 1 receptor knockout mice are protected from stress-induced hair growth inhibition. J. Mol.
Med. 83:386-396.

94. Arck, P.C., Slominski, A., Theoharides, T.C., Peters, E.M., and Paus, R. 2006. Neuroimmunology of stress: skin takes center stage. J. Invest. Dermatol. 126:1697-1704.

95. Peters, E.M., et al. 2004. Neurogenic inflammation in stress-induced termination of murine hair growth is promoted by nerve growth factor. Am. J. Pathol. 165:259-271.

96. Peters, E.M., et al. 2006. Neuropeptide control mechanisms in cutaneous biology: physiological and clinical significance. J. Invest. Dermatol. 126:1937-1947.

97. Peters, E.M., et al. 2007. An in vitro model for the exploration of cutaneous stress responses: substance $\mathrm{P}$ inhibits hair growth, induces mast cell degranulation, up-regulates p75NTR expression and causes immune privilege collapse in vitro [abstract].
J. Invest. Dermatol. 127(Suppl. 1):S109.

98. Siebenhaar, F., et al. 2007. Substance P as an immunomodulatory neuropeptide in a mouse model for autoimmune hair loss (alopecia areata). J. Invest. Dermatol. 127:1489-1497.

99. Hordinsky, M.K., Kennedy, W., WendelschaferCrabb, G., and Lewis, S. 1995. Structure and function of cutaneous nerves in alopecia areata. J. Invest. Dermatol. 104(5 Suppl.):28S-29S.

100.Tang, L., Cao, L., Sundberg, J.P., Lui, H., and Shapiro, J. 2004. Restoration of hair growth in mice with an alopecia areata-like disease using topical anthralin. Exp. Dermatol. 13:5-10.

101.Tang, L., Lui, H., Sundberg, J.P., Bissonnette, R., McLean, D.I., and Shapiro, J. 2003. Restoration of hair growth with topical diphencyprone in mouse and rat models of alopecia areata. J. Am. Acad. Dermatol. 49:1013-1019. 